\title{
Framing Trend and Style Information in Magazine
}

\author{
Yoo Jin Kwon ${ }^{\dagger}$ \\ Dept. of Home Economics, Korea National Open University \\ Received December 26, 2012; Revised April 23, 2013; Accepted May 20, 2013
}

\begin{abstract}
This study applies framing theory to the presentation of trend or styling information in fashion journalism. A qualitative content analysis was conducted with three lifestyle magazines. The findings include attribute, attitude, and source-based frames. The attribute-based frame was used to increase the versatility and feasibility of design by emphasizing particular attributes of clothes. To increase versatility, an item could be presented either as a basic or trendy design. To increase feasibility, fashion information could be customized by price points (i.e., affordable frame) or body type (i.e., flattering frame). The attitude-based frame includes prescriptive and rule-breaking frames. The source-based frame offers a source of trend or styling information. Expert, celebrity, and consumer frame emerged under the source-based frame. Findings reveal how fashion and style information is defined and crafted.
\end{abstract}

Key words: Framing, Fashion, Fashion journalism, Magazine, Style information

\section{Introduction}

Change is inevitable in fashion. Classic fashion theories focus on understanding the causes of fashion change. Simmel (1957) argues that fashion changes come from the pursuit of individuality and collectivity. His viewpoint is based on the dual need for differentiation from and identification with others. Blumer (1969) interprets the adoption of new fashion as change in collective taste in which the diffusion of fashion trends is institutionalized. New trend information is systematically forecasted by going through multiple institutions until it reaches end users. Consumers are exposed to new trends through new product display at retail stores, media coverage, and interpersonal communication. Among these channels, mass media is by far the most important source of information about fashion. The current study is particularly interested in the provision of information in magazines. Magazines are important in fashion journalism, not only because

Corresponding author

E-mail: kwonyoojin@knou.ac.kr they feed fashion and style information to end consumers, but also because the presentation of information in magazine provides an editorial frame for fashionrelated contents in other media including television and social media.

This study investigates how fashion and style information is framed in American popular magazines. The research question of the study is to investigate what type of frame that fashion journalism adopts. To do so, the current study examines the fashion and style sections in magazines that have a general readership. Fashion and styling is a popular subject in general magazines, not just in high fashion magazines. In 2011, editorial pages related to "wearing apparel/accessories" comprised $13.1 \%$ of the entire number of editorial pages, ranking second only to the number of pages devoted to "entertainment/celebrity" (Hall's Magazine Reports, 2012).

Consumers consciously and unconsciously are exposed to new styles through the magazines. The way in which information is presented shapes and is shaped by consumers' perception of fashion and style information. This study analyzes how the contents of

(C) 2013, The Korean Society of Clothing and Textiles. All rights reserved. 
fashion and style sections are created and how the information is tailored for its audience.

\section{Literature Review}

Framing theory is one of the theories that explain the effects of mass media on audience perception on issues. Frame is "a central organizing idea for news content that supplies a context and suggests what the issue is through the use of selection, emphasis, exclusion, and elaboration" (Severin \& Tankard, 2001, p. 277). Media framing was conceptualized to explain various ways in which the news media cover the same issue and big perceptual differences that the frames create on controversial issues. For example, abortion is disputed as it regards to the life of an unborn child, whereas abortion is deemed a woman's right to choose for her and her body (Severin \& Tankard, 2001). Audience of mass media is exposed to news contents that are carefully selected and crafted by the media. Framing can have an impact on the interpretation of an issue and the persuasiveness of the message.

From an audience standpoint, frame serves as a schema of interpretation and framing is necessary to reduce the complexity of an issue and make information easily accessible to a lay audience (Scheufele \& Tewksbury, 2007). A frame has four functions (Entman, 1993). Frames define an issue, diagnose causes of the problems, make moral judgments on the problems, and suggest remedies for the problems.

Numerous studies in communication have identified frames that are used in news content and the effects of framing on formation of public opinion particularly for controversial issues. For example, health care-related issues could be framed either as an ethical or as a material issue. The ethical frame relates the issue with human rights and ethics associated with health care, while material frame emphasizes costs and benefits to society and indirectly, to individuals (Shah et al., 1996). When news coverage on terrorism focuses on discrete events (e.g., scene of aircraft hijacking, bombing), it assigns responsibility for the social problems to individuals or groups. However, news coverage analyzes it as a general political problem such as economic oppression or politics, implying that society as a whole is responsible (Iyengar, 1991).

Framing theory has been tested in consumer behavior research. Charitable donations can be presented either in dollar amounts or as percentages of a sale price (Lee \& Chang, 2008). The redemption window in a sales promotion can be framed as expansive (e.g., "anytime between noon and 4") or restrictive (e.g., “only between noon and 4") (Cheema \& Patrick, 2008). In addition to the effect of framing, these studies find moderation effects. Framing can be implemented with regard to the way the information is presented as seen in the donation and sales promotion, or framing can affect the cognitive process of audience as seen in the news coverage.

In contrast to communication field, little research effort in clothing and textiles field has been made. Literature on appearance in relation to media effect has centered on the impact on self-concept, including self-esteem and body image (Groesz et al., 2002; Jung, 2006; Kim \& Lennon, 2007). The majority of these studies have tested the effect of exposure to idealized images portrayed in the media, but have only inconsistent findings in regard to the influence of exposure on body image or self-esteem. These studies pay attention to the contents in the media per se (e.g., ideal versus actual consumer image or types of advertising appeals) (Fangman et al., 2004).

Throughout the history of fashion, the role of magazine has been significant in disseminating new style information. In the eighteenth century, journals that contained sketches of dresses at the French court were reproduced and distributed across Europe. The role of fashion journals continued to expand in the nineteenth century. Fashion magazines were read by a popular audience. The European fashion, particularly Paris fashion, was delivered to the United States via fashion magazines. Harper's Bazaar began showing the work of French couture in the U.S. in 1867 and Vogue started providing both illustrations and patterns for American dressmakers and consumers to replicate in 1892 (Ward, 2009). Since then, these global magazines have been published in many countries.

Currently, fashion and style information is produced on television, in newspapers, and on the Internet. With the Internet, self-publishing and blogging have become 
means of producing fashion and style information. Regardless of the type of media, fashion and style information is organized and presented in several typical formats. I believe magazines, as the oldest medium that has provided style information, have historically provided the frames and it is not difficult to find an editorial trace of magazines in various types of fashion information.

Drawing upon framing theory, this study is to identify frames for style and trend information used in fashion journalism. The findings will reveal how diverse and constantly changing style information is processed for consumers. The significance of this study lies in uncovering how and why fashion and style information is defined and crafted in certain ways and providing implications for journalists as to ways to make the information more valuable and credible.

\section{Methods}

Qualitative content analysis of the media was conducted for the research. Rhetorical analysis of editorial pages is appropriate in order to identify what devices are used in forming fashion and style sections in magazines. In order to control for peculiarities of a particular magazine, the researcher decide to consider three top-selling monthly magazines for analysis based on three criteria: (1) A majority female readership; (2) fashion is one of the main subject areas of the magazine; (3) a popular readership. In terms of circulation, Cosmopolitan, Glamour, and Seventeen are the top three magazines that meet all three criteria (i.e., female readership, fashion as a main section, and popular readership). These magazines are ranked $15^{\text {th }}, 23^{\text {rd }}$, and $33^{\text {rd }}$, respectively, in average circulation combining subscription and single copy circulation in the U.S. for all magazines in 2011 (The Association of Magazine Media, 2012). Because the statistics encompass the data of magazines of all subject matters including politics, economics, game, entertainment, sports, cooking, and lifestyle, the three titles selected for this study are the actual top three magazines that meet the criteria. The following provides details of the selection process.

High-circulation magazines for women are two kinds: lifestyle magazine or so-called the Seven Sisters. The Seven Sisters refers to magazines which have traditionally been aimed at married women who are homemakers with husbands and children. The Seven Sisters feature articles on health, cooking, diet, gardening, and relationship advices. Lifestyle magazines have a variety of sections including fashion, beauty, entertainment, health, and life coaching. In lifestyle magazines such as Cosmopolitan and Glamour, fashion is one of the main sections. However, the Seven Sisters, such as Better Homes and Gardens, Good Housekeeping, or Woman's Day does not cover fashion as a major contents or their fashion section rather focuses on grooming and sewing reflecting traditional roles of homemaker. Although Better Homes and Gardens, Good Housekeeping, and Woman's Day, are rated higher than lifestyle magazines (i.e., $3^{\text {rd }}, 7^{\text {th }}$, and $8^{\text {th }}$, respectively), the researcher excluded magazines of the Seven Sisters from consideration. After excluding the Seven Sisters, the top three women's magazines are Cosmopolitan, Glamour, and Seventeen.

Among the three magazines selected, Cosmopolitan and Glamour target women in their 20s through 40s, specifically single and working women who are considered major consumers of fashion and apparel industry. Seventeen has mainly a female teenage audience. It is the top general lifestyle magazine among teenagers. In result, the magazines selected include contents created for wide age groups.

The researcher chose to analyze magazines that have popular readership, which results in excluding titles that are considered fashion magazines (e.g., In Style, Vogue, or Elle). Because these magazines target readers with special interests in fashion or professionals in the field, trend and styling information is expected to be crafted in different manners for the readers with expertise. Because of the limited range of the actual audience, none of the fashion magazines are ranked higher than leading general lifestyle magazines in terms of circulation.

The three magazines analyzed first published in the United States. They are currently distributed in a number of countries with their international editions. Cosmopolitan has 64 international editions and is distributed in more than 100 countries ("Cosmopolitan," 2013). 
Glamour has 12 international editions ("Glamour," 2013) and Seventeen has 6 international editions ("Seventeen," 2013). In addition to the impact on American consumers, global distribution implies their influences on the editorial frame and rhetorical strategies in other countries.

The number of issues analyzed was limited to sixty (i.e., twenty issues per title) due to limitations of resource. Data was coded manually, which also creates limitations on the size of the data. In selecting issues from each title, the researcher wanted to minimize any potential effects of season, because editorials related fashion are carefully planned based on seasonal issues. Therefore, the researcher decided to select four issues randomly for each year rather than the lesser number of issues for each year over the longer period. Issues of each year were selected by a random number generating program. As a result of random number generation, 14 issues were selected from spring season, 13 from summer season, 18 from fall season, and 15 from winder season. In sum, four randomly selected issues over the five year period were selected for the three magazines. All editorial pages related to fashion trends and styling in each issue were analyzed. Visuals and texts including headings, captions, and main body of 891 pages - 202 pages from Cosmopolitan, 356 pages from Glamour, and 333 pages from Seventeen - were analyzed.

The researcher first conducted open coding; the research made a note of potential categories of frame that describes the way a clothing item is presented by examining visuals and texts page by page. Based on the result of open coding, the preliminary coding guide was identified and organized to make a category system. Then the category system was tested by coding the data to see if the concept of each category is relevant and clear. As qualitative data analysis involves an iterative process, the category system had been revised multiple times by going back and forth between the category system and the data until the concept and the hierarchy of categories became solid. The data were coded using the coding system developed. From a peer review process, the completeness of the category system was questioned, as the frames were found only from half of the data. Then, the researcher went back to data and revised the category system. In result, one set of frames was added and there was minor revision to the previous categories. After the revised category system was examined by a third party expert in the field to ensure trustworthiness, the category system was finalized. Finally, the data were coded with the final category system of frame.

\section{Findings and Discussion}

Three types of frame emerged: attribute-based, attitude-based and source-based frame, based on the editorial goal for an article. Under the attitude-based frame, versatility and feasibility frame emerged. Versatility, feasibility, attitude-based, and source-based frame was located on $16 \%, 22 \%, 16 \%$, and $41 \%$ of the pages analyzed, respectively. In total, $72 \%$ of the pages include one or more type of these frames.

Attribute-based frame capitalizes on desirable attributes of clothing, such as style, price, and body-type in presenting fashion and styling information. Two types of attribute-based frame emerged: versatility and feasibility. The former presents how versatile a style or an item can be, how to put basic and trendy items together, or how to wear trendy clothes in various contexts. The latter presents feasible strategies or plans to stay in style by helping to find products according to consumers' budget and their body type. Under versatility frame, three sub-categories emerged: basic, tren$\mathrm{dy}$, and context-setting. Under feasibility, two emerged: affordable and flattering.

Attitude-based frame refers to a mode of presenting fashion and style information by addressing the consumer's attitude towards style. Sub-categories of attitude-based frames were named after the two ambivalent attitudes that human beings hold toward fashion: prescriptive and rule-breaking. Prescriptive frame appeals to human needs to conform to norms of society, while rule-breaking frame appeals to human needs to be different from others. The former provides information as to how to dress up-to-date reflecting general trends. On the other hand, the latter provides information as to how to dress unique nominally going against general trends. 
Source-based frame capitalizes on the source effect in communication and persuasion. It refers to providing trend information along with its source such as designers' runway pictures, celebrities, or lay people. Three types of source-based frame emerged based on the nature of the source: expert, celebrity, and typical consumer. In terms of frequency, source-based frames are used most often located in more than $40 \%$ of the pages. Attribute- and attitude-based frame are about the contents of articles, while source-based frame is to reinforce credibility of the contents. Source-based frame is often combined with the other types of frame. Thus, the sum of coded pages of each frame is greater than the total number of pages coded with frames. The use of frames is summarized in $<$ Table $1>$.

\section{Versatility Frame: Basic, Trendy, and Con- text-setting}

The versatility frame conceptually positions the style of a product in reader's mind. The goal of versatility frame is to increase the perceived value of the style by demonstrating ways to make better use of an item. That is, it illustrates the versatility of the design. Consumers value the versatility of a clothing item. When people make a purchase decision of clothes, they want to know how useful the clothes would be: how well that piece would go with other items they already own and how well the piece would fit various contexts.
Versatile clothes or new styles that look versatile are adopted by consumers easily and they think those worth investing. Three kinds of versatility frame were identified: basic, trendy, and context-setting. The use of versatility frame is summarized by title in $\langle$ Table $2>$.

A basic frame features the most common styles or items, such as little black dresses, trench coats, or blue jeans. Key words found in basic frame include basic, staples, and classic. The basic frame emphasizes how versatile, fashionable, and thus up-to-date these can be when they are coordinated with other items. Typically an item of interest is put together with various types of design so that readers can picture diverse occasions when they can wear the item. As seen in $<$ Fig. 1>, a format such as "New ways to wear X" or "4 ways to wear X" displays the transformation of a basic item into diverse looks. The upper picture of $<$ Fig. $1>$ proposes various style examples of LBD, acronym for little black dress. As this classic item is characterized by its color, the article introduces ways to put LBD with items of different colors. The bottom picture of $<$ Fig. $1>$ presents four examples of styling a basic tank top: girly, boho, sporty, and edgy. The versatility presents the heightened use value of the item, because the consumer would wear the tank top on different occasions.

In addition to presenting usability of a basic item, another strategy of basic frame is expanding the concept of basic. The boundary of classic item is vari-

Table 1. The use of frames

\begin{tabular}{c|c|c|c|c|c}
\hline \multirow{2}{*}{ Magazine of frame } & \multicolumn{2}{|c|}{ Attribute-based Frame } & \multirow{2}{*}{$\begin{array}{c}\text { Attitude-based } \\
\text { Frame }\end{array}$} & $\begin{array}{c}\text { Source-based } \\
\text { Frame }\end{array}$ & $\begin{array}{c}\text { Total Pages Coded } \\
\text { with Frames }\end{array}$ \\
\cline { 2 - 3 } & Versatility & Feasibility & $37(18 \%)$ & $84(42 \%)$ & $153(76 \%)$ \\
\hline Cosmopolitan & $46(23 \%)$ & $24(12 \%)$ & $62(17 \%)$ & $110(31 \%)$ & $222(62 \%)$ \\
\hline Glamour & $42(12 \%)$ & $54(15 \%)$ & $43(13 \%)$ & $175(53 \%)$ & $268(80 \%)$ \\
\hline Seventeen & $58(17 \%)$ & $115(35 \%)$ & $142(16 \%)$ & $369(41 \%)$ & $643(72 \%)$ \\
\hline Total & $146(16 \%)$ & $193(22 \%)$ & & & \\
\hline
\end{tabular}

Table 2. The use of a versatility frame

\begin{tabular}{c|c|c|c}
\hline \hline Sugazine & Basic & Trendy & Context-setting \\
\hline Cosmopolitan & $24(12 \%)$ & $8(4 \%)$ & $23(11 \%)$ \\
\hline Glamour & $15(4 \%)$ & $6(2 \%)$ & $24(7 \%)$ \\
\hline Seventeen & $16(5 \%)$ & $14(4 \%)$ & $35(11 \%)$ \\
\hline Total & $55(6 \%)$ & $28(3 \%)$ & $82(9 \%)$ \\
\hline
\end{tabular}




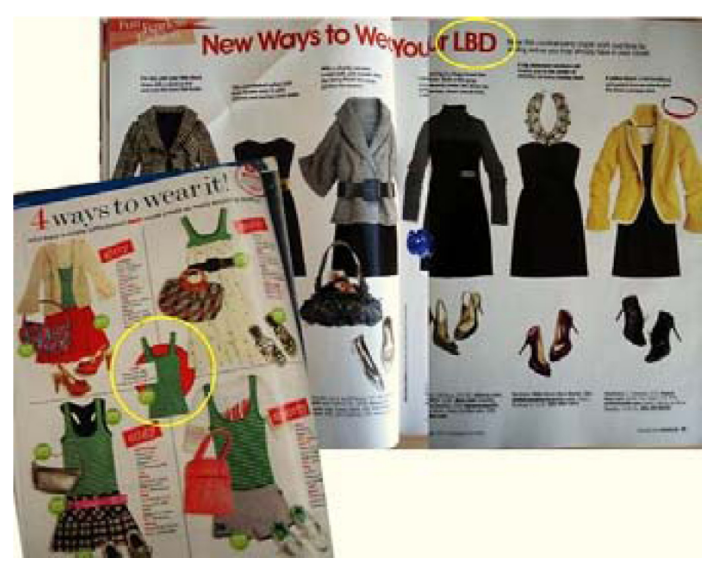

Fig. 1. Basic frame.

From New ways to wear your LBD.

(2008, June). Seventeen, p. 44.

From 4 ways to wear it!

(2008, December). Cosmopolitan, p. 84-85.

able. Some articles present a popular style of the time as new basics, supplementing the scope of basics with new design. Although new basic items are not necessarily classic pieces, they are positioned as part of the basics in one's wardrobe. Those articles presents how easy it is to accessorize the new basic items.

Another strategy of expanding basics is to work on an item or material itself. A classic trench coat is defined with certain design elements (i.e., wide lapels, a storm flap, straps around the writs, belted and made of khaki heavy duty cotton gabardine). Owing to the concept that a trench coat is classic, variations on this trench coat are presented sending the message "trench coats are versatile." Denim products are often presented using this frame. Among denim products, denim pants or blue jeans are considered basic. Because American consumers are so familiar with denim, magazines sometimes have an article for various items made of denim including jacket, skirt, dress, and more. These items are made for more formal look as well as casual look, presenting the versatility of denim. Or various cuts of denim pants are presented in the similar manner.

It is not the only purpose of using the basic frame to promote basic design. The basic frame is fairly useful for the integration of new fashion trends. Editors select basic styles that are compatible with current trends. Basic design is partnered with a variety of trendy designs. Therefore, articles with the basic frame promote many different trendy items.

The trendy frame emphasizes how compatible a trendy design can be with other designs. The item selected is usually new design in the market. Like the basic frame, the format of trendy frame introduces multiple ways of wearing an item. A main item is matched with basic and classic item as well as other trendy designs. Seen in the left example of $<$ Fig. $2>$, the article presents a shiny flared skirt as "trend of the month" and illustrates different types of tops to pair with it, including a dressy sleeveless top, classic white shirts, a feminine lace blouse, a staple turtle neck, a tweed jacket for work, and a casual cardigan. This example is to provide information to wear this new design in different occasions. Although a reader may not own all the items suggested, the reader can picture the use of the design and understand the value of the item.

Similar to the basic frame, the trendy frame sometimes underlines many ways in which the new design can be worn. Consumers, except for early adopters, are usually hesitant about trying out new designs. The right example of $<$ Fig. $2>$ shows that the white slip-on at the center is useful in creating four different looks. Presenting a new design using trendy frame can be persuasive and educational for these consumers. Consumers can learn the aesthetic value of the new style through this type of presentation.

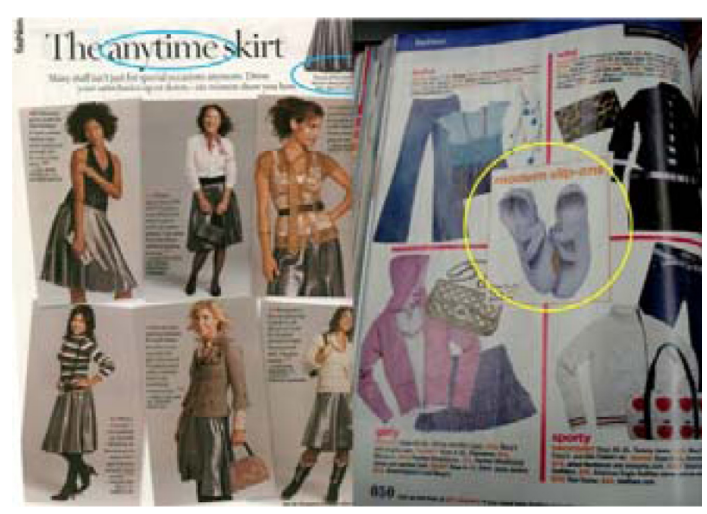

Fig. 2. Trendy frame.

From The anytime skirt.

(2005, December). Glamour, p. 112.

From Modern slip-ons.

(2004, September). Seventeen, p. 50. 
Tight-roping between basic and trendy frame is a strategic tool that permits information on any styles. Almost any item can be presented either in basic and trendy frame. Basic and classic design would be presented as a central item using basic frame, and trendy and new design would be presented as a central item using trendy frame. Interestingly, both frames require the presentation of basic and trendy items, although the role of each type of design may differ in each frame. In other words, basic designs also take a role of supporting piece for a trendy item in trendy frame and trendy designs are presented as a supporting piece for a basic item in basic frame. Therefore, editors can provide diverse designs using versatility frames. The difference is which feature (i.e., basic vs. trendy) an editor wishes to capitalize on.

The boundary of basic and trendy is relative and variable. Whether a product is basic or trendy is subject to a consumer's perception and usage and it also varies by age. Basic items of Seventeen is particularly different from the other two titles. Miniskirt or items of school uniform look is treated as basic for teenagers. Even for adult consumers, trendy items that stay for a long time are considered basic such as capri pants or cropped jacket. It was difficult to tell whether basic or trendy frame for articles on some of the long-lasting styles of items. In this case, coding was conducted based on texts of the articles.

A context-setting frame is a way of grouping clothing and accessories by their usage. Contexts that appeared frequently were workplace for adults, followed by outfits for date, travel, beach, and night-out. The left example of $<$ Fig. $3>$ illustrates a typical way of proposing appropriate clothes for work and the right example of $\langle$ Fig. $3>$ is a pictorial of prom dresses. For teenagers and young adults, prom, school clothes, Halloween, and homecoming day were important occasions. Examples of headings are "10 Sexy Date Buys", "What to wear to work today", "Your Getaway Style", and "Your perfect prom dress". These contexts are the ones in which consumers hold deep involvement. Therefore, presenting new designs for these important occasions would attract reader's attention. Particularly work clothes are carefully recommended in magazine. In addition to simple proposal of work-ap-

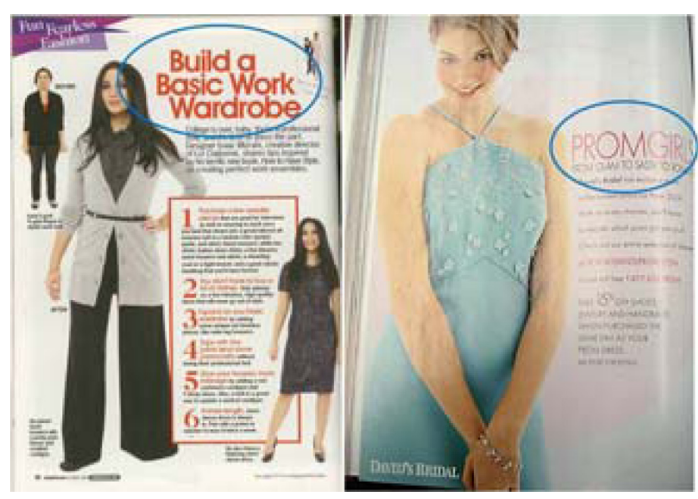

Fig. 3. Context-setting frame.

From Build a basic work wardrobe. (2008, October). Cosmopolitan, p. 98.

From Prom girls. (2008, May). Seventeen, p. 68.

propriate clothes, fine-tuned themes are also found such as "How to wear cool and appropriate in summer" or "How to wear casual items appropriately". This editorial effort, compared to pictorials without particular theme, differentiates the magazine from its competitions. Context-setting frame directly proposes how to wear new designs to consumers. At the same time, context-setting frame requires editor's creativity and aesthetic sense. Many of articles using context-setting frame is instructional in that they integrates dress code and norms of society.

\section{Feasibility Frame: Affordable and Flattering}

The rhetorical goal of feasibility frame is to increase the perceived value of the style by providing solutions to problems or to reduce risks in wearing trendy clothes. Two feasibility frames were identified: affordable and flattering. The former addresses the economic concern and the latter addresses consumers' concern about body image. The use of feasibility frame is summarized by title in $\langle$ Table $3>$.

An affordable frame addresses an issue of price from consumers' side. Price frame would be a correct term to refer to this type of frame. I named it as affordable frame; because the most common message was that a new style can be inexpensive. This kind of frame appeals to an audience on a budget. Articles using the affordable frame encourage readers to adopt 
Table 3. The use of a feasibility frame

\begin{tabular}{c|r|r|r}
\hline Magazine & Affordable & Flattering & \multicolumn{1}{c}{ Total } \\
\hline Cosmopolitan & $21(10 \%)$ & $3(1 \%)$ & $24(12 \%)$ \\
\hline Glamour & $45(13 \%)$ & $9(3 \%)$ & $54(15 \%)$ \\
\hline Seventeen & $74(22 \%)$ & $43(13 \%)$ & $115(35 \%)$ \\
\hline Total & $140(16 \%)$ & $55(6 \%)$ & $193(22 \%)$ \\
\hline
\end{tabular}

new styles. The prototype of a new style is usually selected from a high-end designer's runway collection. For a popular audience, the media provide a less expensive version of the same style. Brand name and price information is usually provided along with stylistic characteristics. Runway or celebrity visuals used in affordable frame provide assurance for consumers on a tight budget.

The left example of $<$ Fig. $4>$ displays a photo of a celebrity wearing denim jacket as a reference and provides denim jackets in three different styles. In each style, the editor show two different versions, distinguishing high and low priced examples, or "Spend" and "Save". The right example of $<$ Fig. $4>$ presents three different versions of a style, a runway version, a look for a celebrity, and one for the audience. The runway and the celebrity version endorse the trend and the audience version delivers the message, "Here is what you can afford to synchronize your style with up-to-date fashion". It reflects the influence of high fashion and trendsetters on mass fashion.

The affordable frame is not always to serve bargain-

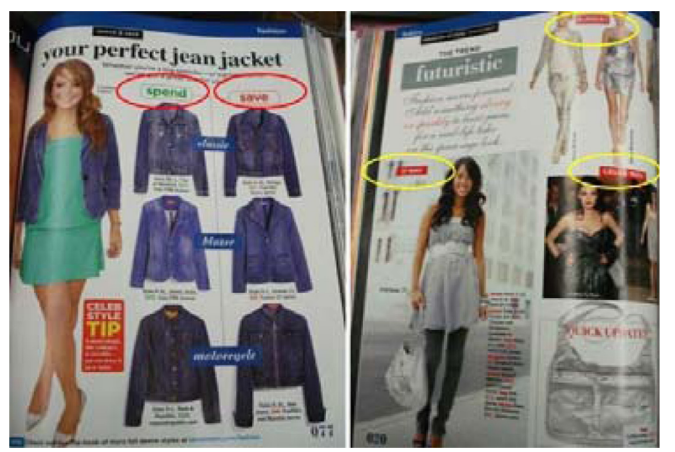

Fig. 4. Affordable frame.

From Your perfect jean jacket. (2004, September). Seventeen, p. 77.

From The trend futuristic.

(2007, February). Seventeen, p. 20. hunters. By framing based on price, fashion and style articles display products of the same style at various price points. In Cosmopolitan and Glamour, diverse attitudes toward fashion products are reflected in the way the contents are framed: for example, "steal, spend, and splurge" version of a style. A "steal" version is inexpensive. A "spend" version is more expensive. A "splurge" version refers to the most costly version of the style. Providing the diverse versions (i.e., steal vs. spend vs. splurge) delivers a message that anyone can afford the style, depending on how much she is willing to spend on it. In other words, the articles denote that fashion has it all; legitimate knock-offs, investment pieces, or luxury goods.

Another feasibility frame was the flattering frame. The rhetorical strategy of this frame is that there is a style for every body type. Flattering frame customizes style information for body type. This type of articles proposes styles for each body type (e.g., hourglassshaped, pear-shaped, inverted triangle-shaped, tall, petite, or slender) or solutions for problem areas (e.g., waist, thigh, or leg). The left example of $<$ Fig. $5>$ presents various jacket designs that work for different body types. As the range of type and size of body is much wider in Western society, this type of information is expected to be more important to readers in multi-cultural society such as America. In addition to proposing a solution to the weak point in one's body, another strategy is to share styling tips of making the

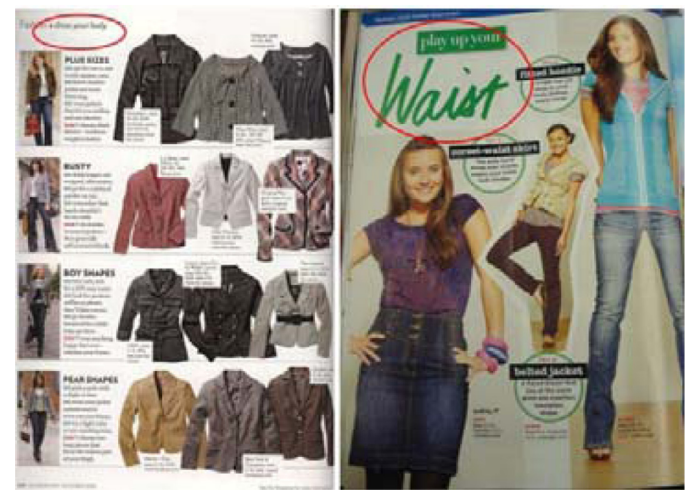

Fig. 5. Flattering frame.

From Dress your body.

(2008, November). Glamour, p. 122.

From Play up your waist.

(2008, October). Seventeen, p. 42. 
best of one's strong point in the body. Considering the growing interests in appearance including toned body, workout, and dieting among consumers of Eastern culture, styling tips of complementing one's figure continues to be important both in the East and the West. Flattering frame particularly involves rearrangement of trend and style information. The contents of articles are likely to reflect creativity and viewpoint of editors.

The feasibility frame was located much more often in Seventeen compared to the other two titles. Thirtyfive percent of the pages in Seventeen adopted the feasibility frame, while $12 \%$ and $15 \%$ in Cosmopolitan and Glamour did, respectively. The difference is interpreted in two ways. Adolescents tend to be more enthusiastic about adopting new trends, but they are still financially dependent on parents. Teenagers are therefore interested in affordable fashion. Interestingly, flattering frame was also more prevalent in Seventeen. It is because adolescents are particularly conscious of their new body image. By using flattering frame, mass media skillfully meets their needs and integrates this concern into the presentation of style information.

\section{Attitude-based Frame: Prescriptive and Rule- breaking}

Two frames that capitalize on the ambivalent nature of fashion emerged: prescriptive and rule-breaking. While versatility and feasibility frames pivot on attributes of products and consumers, respectively, prescriptive and rule-breaking frame reflect attitudes that consumers hold toward fashion. The use of attitude-based frame is summarized by title in $<$ Table $4>$.

Prescriptive frame appeals to a human need for affiliation. Prescriptive frame presents information on what to possess and how to put together in order to

Table 4. The use of an attitude-based frame

\begin{tabular}{c|r|r|c}
\hline Magazine & Prescriptive & $\begin{array}{c}\text { Rule- } \\
\text { breaking }\end{array}$ & Total \\
\hline Cosmopolitan & $34(17 \%)$ & $6(3 \%)$ & $37(18 \%)$ \\
\hline Glamour & $42(12 \%)$ & $20(6 \%)$ & $62(17 \%)$ \\
\hline Seventeen & $29(9 \%)$ & $19(6 \%)$ & $43(13 \%)$ \\
\hline Total & $105(12 \%)$ & $45(5 \%)$ & $142(16 \%)$ \\
\hline
\end{tabular}

be in fashion. "Being in fashion" here means following the fashion rules of the majority. Two typical formats of prescriptive frame are found. One is listing editor's pick of the month and the other is drawing distinctions between right and wrong in styling. By listing up important items of the season or month, editors urge a reader to own certain styles or items, by calling them "essential items" or "must-haves". Some prescribe what is up-to-date comparing with what is outdated, that is, what is in or out. $<$ Fig. $6>$ exemplifies the list-up information. The left picture introduces 7 items as "essentials" and a group of items is called "the It list" in the right picture.

The latter type of prescriptive frame presents a more normative approach. These articles compare pictures of good and bad examples of a styling issue or calling them after and before, respectively. Some magazines have "dos and don'ts" section as their fixed section each month.

Compared to attribute-based frame, items presented with prescriptive frame do not necessarily have stylistic features in common. Styles or items presented with prescriptive frame can be classic, trendy, or something else. Selection of items consists in editor's judgment; editors may include classic design, as it is a staple part of everyone's wardrobe. And they may include something trendy, as its style is adopted by a wide range of consumers. From marketer's point of view, prescriptive frame is most effective when the trend is at an

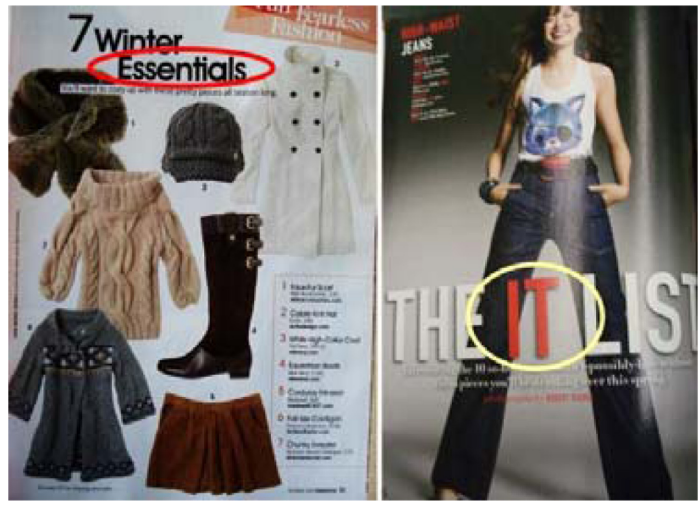

Fig. 6. Prescriptive frame.

From 7 winter essentials. (2008, December). Cosmopolitan, p. 83. From The it list. (2008, March). Seventeen, p. 146. 
early stage in the cycle.

Diversity of trends and styles is the characteristic of the current marketplace. One of the editor's important roles is to sort out trends what could be of use for their readers. Prescriptive frame directly displays the editorial efforts and thus holds the most authoritative tone of voice.

In contrast to prescriptive frame, the rule-breaking frame appeals to individualization. Rule-breaking frames present style information as a guide to stand out and look unique. It is surely appealing to early adopters who have a strong tendency for differentiation. Although messages literally reads going against the norms, the actual message does not encourage being outliers. It encourages readers to be fashionably rulebreaking. Editors pretend to reveal secrets that would place the adopters in a group of trend-setter or those who seek to be stylish but unique.

The left example of $<$ Fig. $7>$ illustrates this adept rhetorical strategy. The headline reads "Fashion rules you can break now." Editors carefully inserted "can" in this headline. The headline holds an authoritative tone as if audience is allowed to be different within limits. At the same time, the right example of $<$ Fig. $7>$ makes an effort to be entertaining for particular consumers. The article proposes suit design for people who do not like to wear suits. Suits are one of the most predictable designs with tailored collar, front

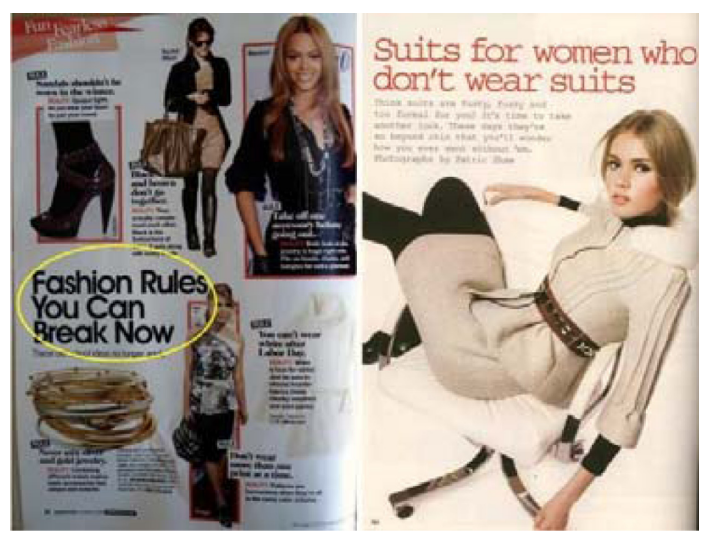

Fig. 7. Rule-breaking frame.

From Fashion rules you can break now. (2008, December). Cosmopolitan, p. 86. From Suits for women who don't wear suits. (2006, November). Glamour, p. 194. opening, and set-in sleeves. There are some occasions where suits are required. The information is intended to suggest suits that will appeal to these consumers. It is highly informative in that consumers learn to select design that satisfies them and is at the same time appropriate. On the other hand, this guidance ultimately keeps those rebellious consumers within the fashion system. The media provides a safe solution to the ambivalence of human being.

Between prescriptive and rule-breaking frames, prescriptive frame is understandably used more frequently than rule-breaking frame (i.e., $12 \%$ for prescriptive and $5 \%$ for rule-breaking frame). One of the roles of fashion section in magazine is to set new trends in reader's mind, establishing order in consumption of fashion products. Prescriptive frame is efficient in performing this role.

\section{Source-based Frame: Expert, Celebrity, and Consumer}

The source-based frame offers a source of trend or styling information. It is similar to spokesperson typically found in news reports or advertising campaigns. There are three types of spokesperson: expert, celebrity, and typical consumers (Solomon, 2011). Experts are believed to be credible, as the information they provide is based on their competence and objectivity. Doctors in pharmaceutical advertisements are one example. Celebrity spokespersons are popular with advertisers because of the attraction that the public feel for the celebrities (Solomon, 2011). Endorsement by typical consumers is also effective, because the typical consumers makes advertising message believable. From the analysis of the current study, the three types of source were similarly located: expert, celebrity, and consumer. The use of source-based frame is summarized in $\langle$ Table 5$\rangle$.

The expert frame introduces fashion trends by putting forward either experts or designers' runway collections. Experts include high fashion designers, editors of fashion magazines, or well-known stylists. A typical expert frame uses experts' work on the runway. The left example of $<$ Fig. $8>$ presents new styles of jacket in a typical form of expert frame. There are 
Table 5. The use of a source-based frame

\begin{tabular}{c|c|c|c|c}
\hline \hline Magazine & Expert & Celebrity & Consumer & Total \\
\hline Cosmopolitan & $49(24 \%)$ & $40(20 \%)$ & $0(0 \%)$ & $84(42 \%)$ \\
\hline Glamour & $65(18 \%)$ & $56(16 \%)$ & $8(2 \%)$ & $110(31 \%)$ \\
\hline Seventeen & $66(20 \%)$ & $56(17 \%)$ & $85(26 \%)$ & $175(53 \%)$ \\
\hline Total & $180(20 \%)$ & $152(17 \%)$ & $93(10 \%)$ & $369(41 \%)$ \\
\hline
\end{tabular}

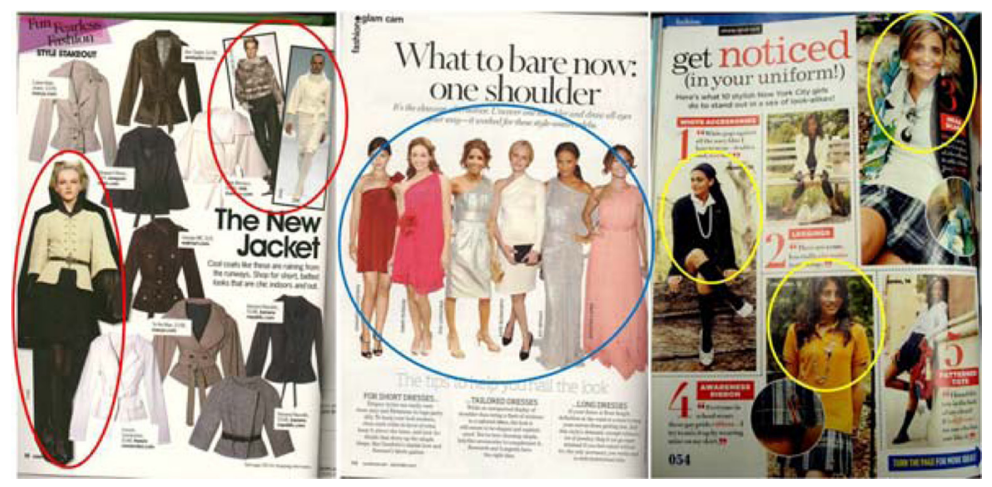

Fig. 8. Source-based frame.

From The new jacket. (2006, October). Cosmopolitan, p. 98.

From What to bare now: one shoulder. (2007, December). Glamour, p. 112.

From Get noticed. (2006, September). Seventeen, p. 54.

items that an editor recommends and runway photos in the same style, displayed side by side. The expert frame is grounded on the trickle-down effect of fashion. High fashion designers' collections functions as references for mass fashion.

The article in the middle of $<$ Fig. $8>$ illustrates a celebrity frame. Star power in the field of fashion does more than just attracting readers. Celebrities are generally considered trend-setters; consumers are likely to gauge fashion by what stars wears. Often times, clothes worn by celebrities are same as those on the runway. That is, celebrities often wear designer labels. However, the message of celebrity frame is different from that of expert frame. Presentation by the celebrity frame signifies the adoption of a style, while presentation by the expert frame signifies the proposal of the style. Seeing clothes in the celebrity frame, consumers are assured that the new style is being or will be successfully diffused.

To strengthen source credibility, many articles present both runway and celebrity photos in recommending less expensive products that are more accessible to ordinary consumers. Although designers or celebrities in magazines and commercials seem to function similarly, there is a big difference. Experts and celebrities in commercials are hired to work as spokespeople for a specific brand or company. Although magazines may pay a royalty on publishing runway pictures or snapshots of celebrities, designers are not commissioned to created new designs for a particular magazine nor are celebrities dressed in that style for a particular magazine. For some pictorials, designers or celebrities are photographed by contract. Except for these cases, editors as journalists adopt pictures of runway or celebrities as objective evidence for trend and style information they report.

A consumer frame is the presentation of typical consumers' clothes. Typical consumers become models or stylists in this frame. The right example of $\langle$ Fig. $8>$ depicts the consumer frame. Typical consumers in commercials are more believable in some way; the public sometimes holds source bias against celebrity spokespersons when audience is aware that the celebrity spokesperson is hired for the commercial. For that reason, 
a typical consumer spokesperson is more appropriate for advertisement of some products. On the other hand, the role of a typical consumer in magazine editorials is different. Although consumer models may be rewarded for having name and photographs in a magazine, consumer models are still effective. The appearance of consumer models is closer to that of actual consumers compared to that of professional models on runway or that of celebrities. In addition, the clothes displayed through the consumer frame are usually much more affordable. Therefore, readers are able to obtain a realistic sense of a style and they feel connected with the style.

The source-based frame is often combined with other types of frame. More than $40 \%$ of the editorial pages used one or more types of source-based frame. There was no difference in the use of expert and celebrity frame among magazines. However, Seventeen uses consumer frame much more than the other magazines did. Cosmopolitan and Glamour rarely used consumer frame ( $0 \%$ and $2 \%$, respectively). In $26 \%$ of pages of Seventeen, teenaged consumers modeled for teenage readers. Because teenagers are more influenced by peers than adults, the consumer frame is as effective with teenaged readers as expert and celebrity frames are. First names and age of teenage models are often printed so that readers can identify with them.

\section{Conclusions}

This study is a content analysis of fashion and style information in magazines. The findings include three types of frame: attribute-based (including versatility and feasibility), attitude-based, and source-based frame. Each type of frame had a few subcategories.

The attribute-based frame was intended to increase versatility and feasibility of design by emphasizing relevant attributes of the design. Versatility frame calls attention to the versatile usage of fashion items by positioning products either as basic or trendy or positioning in a context. Versatility frames increase the perceived value of the style and thus conveys confidence in terms of adopting styles that consumers would like. Versatile frame is subject to consumer's perception of the attributes of the designs. As discussed earlier, the same attributes can be perceived as basic at one point and as trendy at another point. A style would be perceived differently by different audience groups. In addition, what is appropriate and stylish for a particular context changes all the time. Editorial efforts should be continually made to provide relevant and insightful information based on the perceptions of the target audience of the time.

Feasibility frame brings attention to more realistic issues in appearance management. Even if consumers are attracted to new design, they do not purchase those unless those clothes are affordable and flattering. Feasibility frame makes a reader assess whether or not she can afford the style or whether it fits. Information is laid out by price points in affordable frame and by body type in flattering frame. Feasibility frame is to draw readers into fashion by making the information relevant to them.

While the feasibility frame appeals to external factors such as price and body type, attitude-based frame is intended to fit the internal needs of consumers. The attitude-based frame uses the ambivalent attitudes that human beings have for fashion. As Simmel (1957) noted, fashion is a means of identification and of differentiation. Consumers possess items that are similar to others as well as items that are different. Thus, style information can be presented to satisfy the need for conformity with trends and the need for uniqueness. A frame that addresses the former need is the prescriptive frame and a frame that addresses the latter is the rule-breaking frame. Some people are more attracted to the information with prescriptive frame to stay in the group and others find information with the rule-breaking frame more interesting to differentiate self from the group.

The researcher maintains that the basic and the trendy frame also serve the ambivalent needs for identification and differentiation. The basic frame can satisfy the need for conformity in that wearing a basic item is an easy way to conform to social norms, whereas the trendy frame can also satisfy the same need in that adopting new trends signifies following collective changes in society. On the other hand, the basic frame can satisfy the need for differentiation in that 
information with the basic frame provides a way of wearing basic design in a unique way. Because the trendy frame provides how to combine trendy and basic designs or how to put together a unique trendy outfit to avoid being a fashion victim, the trendy frame can also satisfy the need for differentiation. Therefore, fashion journalists have to constantly identify attributes of products in the market and reflect the complicated psychology of their audience's clothing consumption.

Lastly, source-based frame reveals a source of the trend information, while attribute-based and attitudebased frame provide editor's interpretation of fashion trends for audience. Three types of source were identified: expert, celebrity, and consumer. Fashion experts, celebrities, and everyday consumers appeared in editorials function as an evidence of emerging trends that the editor introduces. Each source-based frame has its own format. High fashion designers' products are found easily in magazines in various formats, but the expert frame usually applies product images from runway. Pictures from runway take on the sacred presentation of the designer's work. Editors try to capitalize on high fashion designer's role of leading fashion by using runway images. The other two frames present celebrities or consumers who are dressed in a style that the editor chooses. Celebrities as trend-setting individuals reflect emerging trends and typical consumer models look like one of the readers.

Fashion and style sections in magazine are different in that they deal with commodities, which can compromise the credibility of the information. Therefore, a source-based frame is particularly important. Using photos from runways or snapshots of celebrities or listing personal information of consumer models can ensure the objectivity of information. Provision of the sources of contents has the same effect of an endorsement by expert or celebrity spokesperson. Editors mix more than one type of frame in diffusing new information. Unlike the other frames, the source-based frame does not affect the contents of articles. It is thus likely to be used along with other frames.

From the consumer's side, framing makes contents of magazines much more informative and maintains readers' interest. Approximately $28 \%$ of the pages ana- lyzed did not adopt any of the frames identified. These pages present information in a straightforward way; they have headings and product images. They were simply descriptive. Some headings did not deliver much meanings related to clothes or relevant information to wearers. Those headings are filled with adjectives without much intention (e.g., chic, gorgeous, dress-up). Compared to these pages, articles with relevant frames create added value by pointing out stylistic features or tailoring information for their readers.

From publishers' side, the findings of the study present practical implications. The three types of frame are grounded on different components of articles: clothes (i.e., product), consumer (i.e., reader), and contents. Attribute-based frame is grounded on the attributes of products. Attitude-based frame is grounded on the attitudes of the readers and source-based frame is on the source of the contents of the articles. Framing is a way of organizing the data. For publishers, it is particularly important to adopt or create effective frames on the basis of precise and extensive knowledge of these three components.

Product knowledge is beyond simple stylistic or physical attributes of clothes. Publishers should understand the socio-psychological uses of the clothes: what contents readers really want to know from magazines and what attributes of product can resolve problems readers have. As seen in the versatility and feasibility frame, it is important to call attention to right features for consumers out of the selected designs. If a consumer fails to connect with the clothes, not only she is less likely to buy them, but also she is less likely to read the magazine again.

In addition, knowledge of readers will give a publisher an advantage. The attitude-based frame requires more skill of connecting clothes and their meanings to the attitude that would resonate with readers. Although the current study located only prescriptive and rulebreaking frames, the attitude-based frame may consist of a variety of attitudes. Although the frequency was not high, a theme of clothes for appealing to the opposite sex was repeatedly observed in the data. Identification of attitudes related to appearance management can be applied to development of new frames that can differentiate a magazine. Lastly, findings suggest that 
publishers would choose to provide one or more sources of information among expert, celebrity, and consumer according to their needs.

The contribution of this study is to employ framing theory from mass communication studies to investigate various ways to compose trend and style reports in the media. In the field of clothing and textiles, research efforts have been made to examine what is covered in the media. This study is one of the few studies that examine how fashion trends are reported in the media. On the basis of this study, it would be worthwhile to investigate the effect of framing on audience perception and interpretation of contents of trend and style. Because fashion designs contain numerous subtle differences, a product can be framed either as basic or as trendy; as must-have items or unique items depending on where an emphasis is made. The effect of the three different types of trend sources on consumers' perception is also worth investigating.

The limitation of the study is the number of pages and the scope of magazines. In addition, the issues from fall season outnumbered the other seasons. There may have been some influence of season on the counts of frames. The frames identified here are not exhaustive. In each type of frame, there could be more subcategories. The frames analyzed here are for printed media. With emergence of new media, further study is also needed in relation to the presentation and sharing of fashion information among consumers. I contend that the frames emerged in this study are the most frequently used frames and merit further study. As this study investigated lifestyle magazines for women, future study on framing in fashion journalism should include investigation of framing style in the media for men and professional audience.

\section{References}

Blumer, H. (1969). Fashion: From class differentiation to collective taste. The Sociological Quarterly, 10(3), 275291

Build a basic wardrobe. (2008, October). Cosmopolitan, p. 98.

Cheema, A., \& Patrick, V. M. (2008). Anytime versus only: Mind-sets moderate the effect of expansive versus restrictive frames on promotion evaluation. Journal of Mar- keting Research, 45(August), 462-472.

Cosmopolitan (magazine). (2013). Wikipedia. Retrieved March 25, 2013, from http://en.wikipedia.org/wiki/Cosmopolitan (magazine)

Dress your body. (2008, November). Glamour, p. 122.

Entman, R. M. (1993). Framing: Toward clarification of a fractured paradigm. Journal of Communication, 43(4), $51-58$.

Fangman, T., Ogle, J. P., Bickle, M. C., \& Rouner, D. (2004). Promoting female weight management in 1920 s print media: An analysis of Ladies Home Journal and Vogue Magazines. Family and Consumer Sciences Research Journal, 32(3), 213-253.

Fashion rules you can break now. (2008, December). Cosmopolitan, p. 86.

Get noticed. (2006, September). Seventeen, p. 54.

Glamour. (2013). GLAMOUR. Retrieved March 25, 2013, from http://www.glamour.com/

Groesz, L. M., Levine, M. P., \& Murnen, S. K. (2002). The effect of experimental presentation of thin media images on body satisfaction: A meta-analytic review. International Journal of Eating Disorders, 31(1), 1-16.

Hall's Magazine Reports. (2012). 2011 editorial pages by subject. mpa - The Association of Magazine Media. Retrieved December 20, 2012, from http://www.magazine.org/ insights-resources/research-publications/trends-data/magazine-industry-facts-data/2011-editorial

Iyengar, S. (1991). Is anyone responsible? How television frames political issues. Chicago: University of Chicago.

Jung, J. (2006). Media influence: Pre- and postexposure of college women to media images and the effect of mood and body image. Clothing and Textiles Research Journal, 24(4), 335-344.

Kim, J. H., \& Lennon, S. (2007). Mass media and self-esteem, body image, and eating disorder tendencies. Clothing and Textiles Research Journal, 25(1), 3-23.

Lee, Y. K., \& Chang, C. T. (2008). Intrinsic or extrinsic? Determinants affecting donation behaviors. International Journal of Educational Advancement,, 8(1), 13-24.

Modern slip-ons. (2004, September). Seventeen, p. 50.

New ways to wear your LBD. (2008, June). Seventeen, p. 44.

Play up your waist. (2008, October). Seventeen, p. 42.

Prom girls. (2008, May). Seventeen, p. 68.

Scheufele, D. A., \& Tewksbury, D. (2007). Framing, agenda setting, and priming: The evolution of three media effects models. Journal of Communication, 57(1), 9-20.

Seventeen. (2013). Seventeen. Retrieved March 25, 2013, from http://www.seventeen.com/

Severin, W. J., \& Tankard, J. W. (2001). Communication theories: Origins, methods, and uses in the mass media (5th ed.). New York: Addison Wesley Longman.

Shah, D. V., Domke, D., \& Wackman, D. B. (1996). 'To thine own self be true': Values, framing and voter decision- 
making strategies. Communication Research, 23(5), 509560 .

Simmel, G. (1957). Fashion. The American Journal of Sociology, 62(6), 541-558.

Suits for women who don't wear suits. (2006, November). Glamour, p. 194.

Solomon, M. (2011). Consumer behavior (9th ed.). Boston: Prentice Hall.

The anytime skirt. (2005, December). Glamour, p. 112.

The Association of Magazine Media. (2012). Total paid \& verified circulation for top $100 \mathrm{ABC}$ magazines. mpa The Association of Magazine Media. Retrieved December 20, 2012, from http://www.magazine.org/insightsresources/research-publications/trends-data/magazine- industry-facts-data/2011-average-total

The it list. (2008, March). Seventeen, p. 146.

The new jacket. (2006, October). Cosmopolitan, p. 98.

The trend futuristic. (2007, February). Seventeen, p. 20.

Ward, R. (2009). The history of the fashion magazine. Fashion art daily. Retrieved June 18, 2013, from http://fashionartdaily.blogspot.kr/2009/11/the-history-of-fashionmagazine.html

What to bare now: one shoulder. (2007, December). Glamour, p. 112.

Your perfect jean jacket. (2004, September). Seventeen, p. 77. 4 ways to wear it! (2008, December). Cosmopolitan, p. 8485.

7 winter essentials. (2008, December). Cosmopolitan, p. 83. 